\title{
Pandemias e comunicação: uma avaliação experimental
}

\section{Carolina Melo ${ }^{1}$}

Sandro Cabral ${ }^{2}$

1 Insper Instituto de Ensino e Pesquisa / PhD Program in Business Economics, São Paulo / SP - Brasil

2 Insper Instituto de Ensino e Pesquisa, São Paulo / SP - Brasil

Na tentativa de conter uma pandemia, comunicação pode ser a chave para o sucesso ou para o fracasso. Informações fragmentadas podem afetar as percepções e comportamentos das pessoas, especialmente em tempos de má comunicação governamental, potencialmente minando os seus esforços colaborativos para impedir a disseminação da doença. Para testar se e como as pessoas se apresentam sensíveis a informações quebradas durante a pandemia da COVID-19 no Brasil, usamos um experimento aleatório junto a 571 respondentes. Nossos resultados apontam que mensagens quebradas, mais pessimistas ou mais otimistas, com relação à pandemia não têm um efeito médio significante nas percepções e comportamentos planejados dos respondentes. Numa análise mais exploratória, no entanto, nossos resultados mostram que certos grupos sociodemográficos são mais sensíveis a tais informações quebradas. Enquanto pessoas com baixo nível de escolaridade reagem a mensagens mais pessimistas com um aumento na chance de elas intensificarem medidas de prevenção, pessoas mais velhas (com 60 anos ou mais) - que compõem o grupo de risco para complicações decorrentes do novo coronavírus - reagem a mensagens mais otimistas com uma grande redução na chance de elas intensificarem medidas de prevenção. Além de contribuir com a literatura de gestão de desastres, nosso trabalho reforça a necessidade de governos centralizarem esforços de comunicação, de forma a garantir que as pessoas estejam munidas com informações completas e precisas para formarem suas percepções e adequarem seus comportamentos a uma crise de saúde pública.

Palavras-chave: COVID-19; comunicação; experimento aleatório.

\section{Pandemias y comunicación: una evaluación experimental}

En un intento por contener una pandemia, la comunicación puede ser la clave del éxito o el fracaso. La información fragmentada puede afectar las percepciones y los comportamientos de las personas, especialmente en tiempos de mala comunicación del gobierno, lo que puede socavar sus esfuerzos de colaboración para prevenir la propagación de la enfermedad. Para testar si las personas son sensibles a la información fragmentada durante la pandemia de COVID-19 en Brasil, utilizamos un experimento aleatorio con 571 encuestados. Nuestros resultados indican que los mensajes rotos, más pesimistas o más optimistas, con respecto a la pandemia no tienen un efecto medio significativo en las percepciones y los comportamientos planificados de los encuestados. Sin embargo, en un análisis más exploratorio, nuestros resultados muestran que ciertos grupos sociodemográficos son más sensibles a dicha información fragmentada. Mientras que las personas con un bajo nivel de educación reaccionan a mensajes más pesimistas con una mayor probabilidad de intensificar las medidas preventivas, las personas mayores (de 60 años o más), que conforman el grupo riesgo de complicaciones resultantes del nuevo coronavirus, reaccionan a mensajes más optimistas con una gran reducción en la posibilidad de que intensifiquen las medidas preventivas. Además de contribuir a la literatura sobre gestión de desastres, nuestro trabajo refuerza la necesidad de que los gobiernos centralicen los esfuerzos de comunicación para garantizar que las personas reciban información completa y precisa para formar sus percepciones y adaptar sus comportamientos a una crisis de salud pública.

Palabras clave: COVID-19; comunicación; experimento aleatorio. 


\section{Pandemics and communication: an experimental assessment}

Communication is a key factor in containing a pandemic. Fragmented information may affect people's perceptions and behaviors, especially in times of governmental miscommunication, potentially jeopardizing efforts aimed at containing the spread of the disease. To test whether and how people have been sensitive to broken information during the COVID-19 pandemic in Brazil, we performed a randomized survey experiment on a sample of 571 respondents. We found that more pessimistic or more optimistic fragmented messages about the pandemic have no overall significant average effect on perceptions and planned behavior of the respondents. The exploratory analyses showed that particular sociodemographic groups are more sensitive to these fragmented messages. While less educated people react to more pessimistic messages with an increased likelihood to intensify prevention measures, people aged 60 or older - the high-risk group for COVID-19 complications - react to more optimistic messages with a reduced probability to intensify prevention measures. Besides providing insights to the public administration literature on disaster management, the results reinforce the need for governments to consistently centralize communication efforts to guarantee that people are equipped with complete and accurate information to form their perceptions and adequate their behaviors towards a health crisis.

Keywords: COVID-19; communication; survey experiment.

\section{INTRODUÇÃO E CONTEXTO}

A pandemia da COVID-19 surgiu como uma das crises globais mais severas da história. Bilhões de pessoas estão confinadas, o vírus é desconhecido e as consequências socioeconômicas são imprevisíveis. Governos ao redor do mundo vêm seguindo as diretrizes da Organização Mundial da Saúde (OMS) e outras recomendações baseadas em evidência para promover medidas de distanciamento social. No entanto, alguns líderes vêm se posicionando contra as evidências científicas e argumentando que a situação não é tão preocupante. O presidente brasileiro, Bolsonaro, chegou a declarar que o isolamento social é um exagero e pode ser mais nocivo à população - devido aos impactos negativos na economia.

Apesar de que muito ainda é desconhecido sobre a epidemiologia do novo coronavírus, existe evidência de que políticas nacionais focadas na mitigação e supressão da transmissão previnem que os sistemas de saúde sejam saturados rapidamente e reduzem a mortalidade expressivamente (Anderson, Heesterbeek, Klinkenberg, \& Hollingsworth, 2020; Walker et al., 2020). Adicionalmente, apesar de potenciais perdas econômicas, intervenções não-farmacêuticas adotadas logo cedo - como

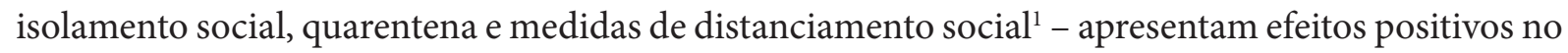
crescimento econômico após uma pandemia, contribuindo para uma recuperação econômica mais rápida (Correia, Luck, \& Verner, 2020). Assim, a prevenção de uma desaceleração econômica nos primeiros estágios de uma pandemia pode custar uma perda econômica muito maior mais tarde, para além da perda de muitas vidas.

Como um complemento à capacidade de se garantir o cumprimento de regras - que garante o confinamento por meio de penalidades e medidas coercitivas -, e similar a outras políticas que têm seus resultados dependentes da participação dos cidadãos (Bovaid, 2007), ações abrangentes que têm como objetivo conter a disseminação de uma doença contagiosa precisam contar com a cooperação da população para coproduzir os resultados desejados (Anderson et al., 2020). No contexto de uma

\footnotetext{
${ }^{1}$ Apesar de reconhecermos as diferenças entre essas intervenções não-farmacêuticas, usamos o termo "isolamento social" no experimento descrito neste artigo para nos referir a qualquer forma mais restrita de distanciamento social.
} 
resposta de saúde pública, para a cooperação ser bem sucedida, pesquisas anteriores indicam que uma estratégia de comunicação bem desenhada precisa estar presente (Clark, Brudney, \& Jang, 2013). Agências governamentais de todos os níveis de jurisdição precisam estar alinhadas e unidas (Comfort, Waugh, \& Cigler, 2012) para, proativamente, comunicar o que se sabe, o que não se sabe e o que está sendo feito para obtenção de mais informações (World Health Organization [WHO], 2020), gerando confiança e mantendo uma reputação sólida. Se, no entanto, as pessoas tiverem de processar por si sós uma quantidade excessiva de informações fragmentadas e incompletas de diferentes fontes - como, por exemplo, programas de televisão, jornais, e mídias sociais -, elas podem chegar a conclusões incoerentes sobre os fatos, potencialmente reduzindo a probabilidade de que recomendações oficiais de saúde serão seguidas e resultando em maior disseminação da doença (World Health Organization [WHO], 2020; McLennan, 2018).

No Brasil, têm-se observado inconsistências nas estratégias de comunicação dos diferentes níveis governamentais. Enquanto governos municipais e estaduais vêm promovendo medidas de distanciamento social e confinamento, de acordo com recomendações de especialistas, a reação inicial do presidente foi contra os conhecimentos já bem estabelecidos na área de gestão de pandemias. $\mathrm{O}$ presidente utilizou de plataformas de mídia nacional para dizer que o isolamento social é um exagero, que a doença provocada pelo novo coronavírus não é perigosa (é apenas uma "gripezinha") e que as atividades econômicas não deveriam parar. Como foi amplamente coberto pela imprensa profissional (Coletta, 2020), o discurso do presidente chocou a comunidade internacional devido às consequências negativas que poderiam ser geradas ${ }^{2}$.

Nós supomos que essas inconsistências têm feito com que a população brasileira fique muito confusa e sensível aos diferentes pedaços de informações que recebe, potencialmente resultando em percepções e comportamentos que podem impedir uma contenção eficaz da disseminação do vírus. Para verificar se a população brasileira tem se mostrado sensível a mensagens fragmentadas sobre a pandemia, realizamos um experimento aleatorizado em uma plataforma de pesquisa, usando informações oficiais da OMS para empregar dois tratamentos diferentes. O tratamento 1 consiste em apresentar aos participantes uma mensagem mais pessimista sobre a pandemia, que diz que as taxas de letalidade podem ser mais altas em alguns países. O tratamento 2, por outro lado, consiste em apresentar aos participantes uma mensagem mais otimista sobre a pandemia, que diz que as taxas de letalidade podem ser mais baixas em alguns países afetados. Se o participante é alocado no grupo de controle, ele recebe uma mensagem geral sobre a pandemia da COVID-19. Então, nós checamos os efeitos médios dos tratamentos sobre a percepção dos respondentes com relação a quão preocupante

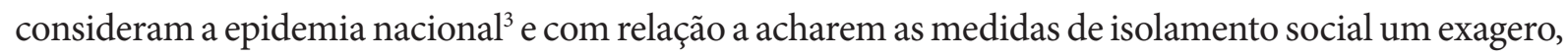
e sobre os seus planos de intensificação das medidas de prevenção nos próximos dias.

\footnotetext{
${ }^{2}$ De fato, outros pesquisadores também usaram de metodologia experimental para mostrar como a comunicação pode afetar as percepções e comportamentos das pessoas. Bursztyn, Egorov, e Fiorin (2020) mostram que o discurso de figuras públicas podem moldar normas sociais. Gross (2008) mostra que a forma como uma mensagem é estruturada pode afetar a resposta emocional das pessoas e, consequentemente, a opinião política dessas pessoas. E Chong e Druckman (2010) mostram que, apesar de que mensagens conflitantes podem anular uma a outra quando recebidas ao mesmo tempo, quando encaram uma sequencia de mensagens ao longo do tempo, as pessoas tendem a colocar mais peso nas mensagens recebidas mais recentemente.

${ }^{3}$ Usamos o termo "epidemia nacional" ao longo do artigo para nos referir, especificamente, à ocorrência de disseminação do novo coronavírus no território nacional brasileiro (onde rodamos a pesquisa).
} 
Naturalmente, espera-se que, se os respondentes são sensíveis a informações fragmentadas, uma mensagem mais pessimista vai aumentar o nível do quão consideram a epidemia nacional preocupante, reduzir a probabilidade de eles acharem o isolamento social um exagero e aumentar a probabilidade de eles planejarem intensificar as medidas de prevenção em um período bem crítico da epidemia nacional. Por outro lado, espera-se que uma mensagem mais otimista vai reduzir o nível do quão consideram a epidemia nacional preocupante, aumentar a probabilidade de eles acharem as medidas de isolamento social um exagero e reduzir a probabilidade de eles planejarem a intensificação das medidas de prevenção quando isso seria muito necessário.

Para além da nossa análise usando toda a amostra de respondentes da pesquisa, também realizamos análises exploratórias para verificar como os tratamentos afetam diferentes grupos de idade, sexo, níveis de escolaridade e níveis de renda.

Os resultados mostram que mensagens fragmentadas mais pessimistas ou mais otimistas não têm um efeito médio significante sobre percepções e comportamentos planejados dos respondentes. Isso sugere que, na média, tais respondentes não são sensíveis aos pedaços de informações aos quais são apresentados. Esses resultados indicam que adultos brasileiros, com um perfil sociodemográfico parecido com aquele do respondente médio, tendem a ser inflexíveis com suas percepções e atitudes com relação à epidemia nacional, mesmo em tempos em que o governo, em diferentes níveis, falha em prover informações consistentes e completas à população.

No entanto, nas nossas análises exploratórias, encontramos resultados diferentes para os diferentes grupos sociodemográficos estudados. Respondentes que não possuem nível superior completo - aqueles com o mais baixo nível de escolaridade da nossa amostra - reagem a mensagens mais pessimistas sobre a pandemia com uma probabilidade mais alta de planejar uma intensificação das medidas de prevenção nos próximos dias. Para o grupo de alto risco para complicações decorrentes da COVID-19 - pessoas de 60 anos ou mais (Chaomin Wu et al., 2020; Onder, Rezza, \& Brusaferro, 2020) -, uma mensagem mais otimista sobre a pandemia causa uma redução substancial na probabilidade de se intensificar medidas de prevenção, potencialmente fazendo com que mais pessoas idosas sejam infectadas e procurem cuidados médicos ${ }^{4}$. Como pode-se notar, uma simples mensagem mais otimista, apresentada a um grupo de pessoas particularmente mais sensíveis, poderia ser a causa de se ter o sistema de saúde saturado.

Nossos resultados são valiosos para informar formadores de políticas públicas interessados em desenhar estratégias de comunicação eficazes para conter a disseminação do vírus e para acadêmicos interessados nos aspectos teóricos de emergências públicas, incluindo esforços colaborativos (Kapucu \& Garayev, 2011), desenho institucional (Boin \& Lodge, 2016), gestão de cadeias de suprimento (Shareef et al., 2019), entre outros.

\section{DADOS E MÉTODOS}

Em 24 de março de 2020, o presidente do Brasil, Bolsonaro, fez um pronunciamento nacional para todos os brasileiros em que se mostrou contra medidas de distanciamento social e diminuiu a severidade a pandemia, indo contra o discurso de autoridades de saúde. Na tentativa de capturar

\footnotetext{
${ }^{4}$ Um aumento no número de pessoas idosas infectadas procurando cuidados médicos pode ser, particularmente, perigoso, porque essas são as pessoas que têm maior chance de precisar de cuidados intensivos, contribuindo para a saturação da capacidade de atendimento nas unidades de terapia intensiva do sistema de saúde.
} 
como informações fragmentadas podem influenciar as percepções e potenciais atitudes da população com relação à epidemia nacional, especialmente em tempos de má comunicação governamental, empregamos uma abordagem experimental.

Usamos uma plataforma online de pesquisa para coletar dados e alocar aleatoriamente participantes em grupos de controle e tratamento, garantindo um desenho experimental ${ }^{5}$. A distribuição da pesquisa foi iniciada na manhã de 26 de março e finalizada na manhã de 28 de março de 2020, mas todas as respostas - com exceção de apenas uma - foram registradas no dia 26 ou no dia $27^{6}$. Residentes de todos os estados brasileiros e do Distrito Federal, de pelo menos 18 anos de idade, foram bem-vindos a responder a esta pesquisa, após concordarem em ter seus resultados anônimos usados para fins de investigação científica, permitindo com que obtivéssemos 571 respostas completas 7.

A pesquisa foi disponibilizada em português e dividida em três partes. Na primeira parte, os participantes foram questionados sobre seus perfis, nos permitindo coletar dados referentes a variáveis sociodemográficas, como idade, raça, nível de escolaridade e nível de renda do domicílio (classe $\mathrm{AB}$ ou classe $\mathrm{CDE}$ ). Na segunda parte, os participantes foram aleatoriamente alocados em um de três grupos: controle, tratamento 1 ou tratamento 2; e, dependendo do grupo em que o respondente foi alocado, ele recebeu uma informação diferente sobre a pandemia da COVID-19. Finalmente, na terceira parte da pesquisa, os respondentes foram questionados sobre suas percepções e comportamentos planejados com relação à epidemia nacional.

Por um lado, o grupo de controle recebeu uma mensagem geral sobre a pandemia, dizendo: Agora, vamos falar especificamente sobre a pandemia de coronavírus. De acordo com o painel de controle da Organização Mundial da Saúde (OMS) ${ }^{8}$ e considerando os dados de 25 de março de 2020, o vírus já chegou em 196 países e sua taxa de letalidade é de 4,46\%. No entanto, essa taxa pode variar bastante entre os países. Por outro lado, os grupos de tratamento receberam ou uma mensagem mais pessimista ou uma mensagem mais otimista sobre a pandemia. O grupo de tratamento 1 recebeu a mesma mensagem que o grupo de controle, mas com uma passagem adicional que dizia: Na Itália e na Espanha, por exemplo, a taxa de letalidade é mais alta. Na Itália, é 9,86\% e, na Espanha, é 6,79\%. $\mathrm{O}$ grupo de tratamento 2 recebeu a mesma mensagem geral que o grupo de controle recebeu, mas com uma passagem adicional que dizia: Na Noruega e na Austrália, por exemplo, a taxa de letalidade é mais baixa. Na Noruega, é 0,39\% e, na Austrália, é 0,33\%. Nessas mensagens, não apresentamos nenhuma informação sobre medidas de contenção da transmissão nos diferentes países, sobre quando tais medidas foram adotadas, sobre o perfil sociodemográfico dos países, e nem sobre a intensidade de testagem da população para presença do vírus. Assim, pode-se considerar que as informações apresentadas aos respondentes da pesquisa eram incompletas e fragmentadas, abertas a uma variedade de abordagens de processamento.

\footnotetext{
${ }^{5}$ Apesar de a validade externa do estudo não ser garantida porque não coletamos uma amostra aleatória da população, a validade interna é garantida pela alocação aleatória realizada dentro da própria plataforma de pesquisa, sem chance de potencial manipulação dos pesquisadores.

${ }^{6}$ A ideia era capturar um momento durante a epidemia nacional em que os cidadãos poderiam estar realmente confusos e sensíveis, devido ao pronunciamento do presidente.

${ }^{7}$ A pesquisa foi distribuída por meio de um link anônimo em plataformas de mídia social. Residentes do Brasil foram convidados a responder à pesquisa de forma voluntária. Após clicarem no link, os respondentes voluntários foram informados que os participantes não seriam identificados e que os resultados da pesquisa seriam utilizados por pesquisadores para investigações científicas somente. Então, se esses voluntários concordassem com os termos apresentados, eles eram convidados a continuar para efetivamente começar a responder às perguntas.

${ }^{8}$ Recuperado de https://covid19.who.int/
} 
Após receber uma das três mensagens descritas acima, o participante respondeu a três perguntas: (1) Numa escala de 0 a 10, o quão preocupante você considera a epidemia do coronavírus no Brasil?;

(2) Você considera que as medidas de isolamento social que estão sendo tomadas são exageradas (sim/ não)?; e (3) Especialistas dizem que a epidemia no Brasil ainda deve piorar antes de começar a melhorar. Você pretende intensificar os cuidados de prevenção nos próximos dias para ajudar a conter a epidemia $(\operatorname{sim} / n \tilde{a} o)$ ?

Essas perguntas nos ajudaram a coletar dados referentes a três variáveis de resultado de interesse:

- Preocupante: uma variável que assume valores de 0 a 10, dependendo do quão preocupante o respondente considera a epidemia nacional, onde 0 significa que ele não considera a epidemia nem um pouco preocupante e 10 significa que ele considera a epidemia extremamente preocupante;

- Exagero: uma variável binária que assume o valor de 1 se o respondente acredita que as medidas de isolamento social são um exagero e o valor de 0 caso contrário; e

- Intensificação: uma variável binária que assume o valor de 1 se o respondente planeja intensificar as medidas de prevenção nos próximos dias para contribuir com a contenção da epidemia e o valor de 0 caso contrário.

Dos 571 respondentes, 190 foram aleatoriamente alocados no grupo de controle, 190 foram aleatoriamente alocados no grupo de tratamento 1 (o grupo que recebeu uma mensagem mais pessimista) e 190 foram aleatoriamente alocados no grupo de tratamento 2 (o grupo que recebeu uma mensagem mais otimista). A Tabela 1 apresenta estatísticas descritivas para todas as variáveis contidas na nossa base de dados final, para todos os grupos combinados, e a Tabela A1 - no apêndice - apresenta estatísticas descritivas para todas as variáveis por grupo ${ }^{9}$. Como pode-se notar, o respondente médio tem 41 anos de idade e uma probabilidade de $83 \%$ de ter menos do que 60 anos. Adicionalmente, o respondente médio tem $70 \%$ de chance de ser do sexo feminino, $69 \%$ de chance de ser branco, $79 \%$ de chance de ter - pelo menos - um diploma de nível superior e $29 \%$ de chance de pertencer às classes A ou B - as classes de mais altos níveis de renda no país. Pode-se notar também que o nível de linha de base do quão preocupante os respondentes julgam ser a epidemia nacional é bem alto, de 8,4 (em uma escala de 0 a 10); o nível de linha de base do percentual de respondentes que julgam a medidas de isolamento social um exagero é bem baixo, de 22\%; e o nível de linha de base do percentual de respondentes que planejam intensificar as medidas de prevenção nos próximos dias é bem alto, de 92\%. Esses níveis extremos de linha de base das variáveis de resultado sugerem que o respondente médio não oferece muito espaço para se tornar ainda mais preocupado com a epidemia nacional, para se tornar menos propenso a julgar medidas de isolamento um exagero e para se tornar mais propenso a planejar a intensificação de medidas de prevenção nos próximos dias.

\footnotetext{
${ }^{9}$ Note que, para que pudéssemos prevenir que os respondentes abandonassem a pesquisa caso não quisessem responder a questão sobre o nível de renda do domicílio, apresentamos nesta questão uma opção que dizia: Não se aplica ou prefiro não responder. Por esse motivo, o número total de observações relacionadas à variável de nível de renda é menor do que o número de observações relacionadas às outras variáveis.
} 


\section{TABELA 1 ESTATÍSTICAS DESCRITIVAS}

\begin{tabular}{|c|c|c|c|c|c|}
\hline Variável & Média & DP & Mín. & Máx. & Obs \\
\hline Preocupante & 8.4816 & 1.8546 & 0 & 10 & 571 \\
\hline Exagero & 0.2137 & 0.4102 & 0 & 1 & 571 \\
\hline Intensificação & 0.9019 & 0.2977 & 0 & 1 & 571 \\
\hline Idade & 41.4011 & 15.2853 & 18 & 84 & 571 \\
\hline $60+$ anos & 0.1646 & 0.3712 & 0 & 1 & 571 \\
\hline Feminino & 0.697 & 0.4599 & 0 & 1 & 571 \\
\hline Branca & 0.6935 & 0.4614 & 0 & 1 & 571 \\
\hline Preta & 0.0473 & 0.2124 & 0 & 1 & 571 \\
\hline Amarela & 0.0263 & 0.1601 & 0 & 1 & 571 \\
\hline Parta & 0.2207 & 0.4151 & 0 & 1 & 571 \\
\hline Indígena & 0.0018 & 0.0418 & 0 & 1 & 571 \\
\hline Ensino Fund. & 0.007 & 0.0835 & 0 & 1 & 571 \\
\hline Ensino Médio & 0.1996 & 0.4001 & 0 & 1 & 571 \\
\hline Ensino Superior & 0.3608 & 0.4806 & 0 & 1 & 571 \\
\hline Pós-graduação & 0.4326 & 0.4959 & 0 & 1 & 571 \\
\hline Classes AB & 0.2901 & 0.4542 & 0 & 1 & 524 \\
\hline
\end{tabular}

Fonte: Elaborada pelos autores.

Para verificar o efeito dos dois tratamentos nas nossas variáveis de resultado de interesse, estimamos a equação de regressão a seguir:

$$
Y_{i}=\beta_{0}+\beta_{1} \operatorname{trat}_{i}+\beta_{2} \operatorname{trat}_{i}+u_{i}
$$

onde: $Y_{i}$ é o resultado do indivíduo $i$; trat $1_{i}$ é uma variável binária que toma o valor de 1 se o indivíduo $i$ está no grupo de tratamento 1 - isto é, se o indivíduo $i$ foi designado a receber a mensagem mais pessimista - e o valor de 0 caso contrário; trat $2_{i}$ é uma variável binária que toma o valor de 1 se o indivíduo $i$ está no grupo de tratamento 2 - isto é, se o indivíduo $i$ foi designado a receber a mensagem mais otimista - e o valor de 0 caso contrário; e $u_{i}$ é o termo de erro robusto para o indivíduo i. Estamos interessados em $\beta_{1}$ e $\beta_{2}$, já que esses parâmetros representam o efeito do tratamento $1 \mathrm{e}$ do tratamento 2 , respectivamente.

Já para verificar o efeito heterogêneo dos dois tratamentos para diferentes grupos sociodemográficos, estimamos a seguinte equação de regressão: 


$$
\begin{gathered}
\text { RAP | Pandemias e comunicação: uma avaliação experimental } \\
Y_{i}=\alpha_{0}+\alpha_{1} \operatorname{trat}_{i}+\alpha_{2} \operatorname{trat} 2_{i}+\alpha_{3} g_{i}+\alpha_{4}\left(g_{i} * \operatorname{trat} 1_{i}\right)+\alpha_{5}\left(g_{i} * \operatorname{trat} 2_{i}\right)+v_{i}
\end{gathered}
$$

onde: $Y_{i}$ é o resultado do indivíduo $i$; trat $1_{i}$ é uma variável binária que toma o valor de 1 se o indivíduo $i$ está no grupo de tratamento 1 - isto é, se o indivíduo $i$ foi designado a receber a mensagem mais pessimista - e o valor de 0 caso contrário; trat $2_{i}$ é uma variável binária que toma o valor de 1 se o indivíduo $i$ está no grupo de tratamento 2 - isto é, se o indivíduo $i$ foi designado a receber a mensagem mais otimista - e o valor de 0 caso contrário; $g_{i}$ é uma variável binária que toma o valor de 1 se o indivíduo $i$ está no grupo demográfico $g$ e o valor de 0 caso contrário; $g_{i} *$ trat $1_{i}$ e $g_{i} *$ trat $2_{i}$ são os termos de interação; e $v_{i}$ é o termo de erro robusto do indivíduo $i$. Agora, estamos interessados em $\alpha_{4}$ e $\alpha_{5}$, já que esses parâmetros nos permitem verificar como os efeitos dos tratamentos mudam quando o indivíduo $i$ está no grupo demográfico $g$.

É esperado que, se os respondentes são realmente sensíveis a informações fragmentadas, eles reajam à mensagem mais pessimista com um nível mais alto de preocupação com relação à epidemia nacional, com uma probabilidade mais baixa de achar que que as medidas de isolamento social são um exagero e com uma probabilidade mais alta de planejar intensificar as medidas prevenção quando momentos críticos estão por vir. Em contraste, é esperado que os respondentes reajam à mensagem mais otimista com um nível mais baixo de preocupação com relação à epidemia nacional, com uma probabilidade mais alta de achar que as medidas de isolamento social são um exagero e com uma probabilidade mais baixa de planejar intensificar as medidas de prevenção nos próximos dias.

A principal hipótese de identificação com relação a nossa estratégia empírica se apoia na exogeneidade das variáveis de tratamento. Isto é, assumimos que o tratamento 1 e o tratamento 2 não são correlacionados com nenhum outro fator que determina os resultados de interesse. Se a aleatorização foi adequadamente conduzida, então essa condição deve ser satisfeita. Testamos se as variáveis de tratamento são exógenas de duas formas: (1) rodando testes de balanceamento e (2) incluindo variáveis sociodemográficas como controles nas regressões principais e verificando se os pontos estimados mudam de forma significante.

Os resultados dos testes de balanceamento são apresentados na Tabela A2 (ver apêndice). Como pode-se notar, o tratamento 1 - o grupo designado a receber uma mensagem mais pessimista - e o tratamento 2 - o grupo designado a receber uma mensagem mais otimista - são muito similares ao grupo de controle. Nenhuma diferença significante é encontrada quando comparamos o grupo de tratamento 1 com o grupo de controle. Encontramos, porém, que a proporção de respondentes que completou até o Ensino Médio e a proporção de respondentes que completou Ensino Superior do grupo de tratamento 2 são significantemente diferentes da proporção de respondentes que completou até o Ensino Médio e a proporção de respondentes que completou Ensino Superior do grupo de controle. Para investigar se essas diferenças podem representar uma ameaça à validade interna do nosso estudo, rodamos nossas regressões principais com e sem controles, e verificamos se os coeficientes mudam significantemente. Como pode-se verificar, os coeficientes de interesse mudam muito pouco quando controlamos para variáveis sociodemográficas - ver Tabela 2 e Tabelas A3 e A4 no apêndice. 


\section{RESULTADOS PRINCIPAIS}

Com relação aos resultados obtidos da estimação da equação de regressão (1), nossa constatação principal está no fato de que, quando consideramos todos os respondentes da pesquisa, nem a mensagem fragmentada pessimista, nem a mensagem fragmentada otimista tem um efeito médio significante nas variáveis de resultado - ver Tabela 2. Isso sugere que pessoas com um perfil parecido com aquele do respondente médio não são sensíveis a pedaços quebrados de informação durante a pandemia da COVID-19. Isto é, essas pessoas não reagem a mensagens fragmentadas com mudanças de percepções e comportamento planejado com relação à epidemia nacional ${ }^{10}$.

\section{TABELA 2 EFEITOS DOS TRATAMENTOS (AMOSTRA COMPLETA)}

\begin{tabular}{lcccccc} 
& $(\mathbf{1})$ & $(\mathbf{2})$ & $(3)$ & $(4)$ & $(5)$ & $(6)$ \\
Variável & Preocupante & Preocupante & Exagero & Exagero & Intensificação & Intensificação \\
\hline Trat 1 & 0.0579 & 0.1712 & 0.0053 & 0.0035 & 0.0000 & 0.0111 \\
Erro Padrão & 0.1952 & 0.1934 & 0.0425 & 0.0431 & 0.0286 & 0.0308 \\
p-valor & 0.7669 & 0.3765 & 0.9015 & 0.9357 & 1.0000 & 0.7195 \\
Trat 2 & 0.0290 & -0.0629 & -0.0116 & 0.0004 & -0.0414 & -0.0359 \\
Erro Padrão & 0.1884 & 0.1968 & 0.0418 & 0.0427 & 0.0314 & 0.0341 \\
p-valor & 0.8775 & 0.7496 & 0.7817 & 0.9928 & 0.1875 & 0.2932 \\
Constante & 8.4526 & 10.2929 & 0.2158 & 1.4218 & 0.9158 & 0.0658 \\
Erro Padrão & 0.1385 & 0.6828 & 0.0299 & 0.2688 & 0.0202 & 0.1459 \\
p-valor & 0.0000 & 0.0000 & 0.0000 & 0.0000 & 0.0000 & 0.6519 \\
N & 571 & 524 & 571 & 524 & 571 & 524 \\
Controles & NÃO & $\mathrm{SIM}$ & NÃ̃ & SIM & NÃO & SIM
\end{tabular}

Notas. Estimações realizadas usando a equação de regressão (1). O conjunto de controles inclui todas as variáveis sociodemográficas coletadas na pesquisa. Erros padrão são robustos.

Fonte: Elaborada pelos autores.

No que se diz respeito a política pública, esse resultado pode significar algo positivo ou negativo. Por um lado, se as pessoas agem de acordo com as melhores recomendações de saúde - baseadas em evidência científica - durante a crise e elas se mantêm firmes com suas percepções e comportamentos apesar da exposição a informações conflitantes transmitidas por oficiais do governo, então o país fica mais propenso a ser bem-sucedido em conter a disseminação do vírus. Por outro lado, se as pessoas agem em desacordo com as recomendações baseadas em evidência, então a nação tem uma chance mais baixa de ser bem-sucedida no controle da epidemia. Além disso, se for o caso de o governo conseguir implementar uma estratégia de comunicação consistente e sólida para encarar a crise de saúde, então essas pessoas não irão reagir às novas instruçães, dificultando a mobilização de esforços colaborativos por parte das autoridades.

\footnotetext{
${ }^{10}$ Vale notar que esse efeito médio não-significante pode se dar, pelo menos em parte, pelo fato de termos níveis bem altos de linha de base para as variáveis de resultado, como descrito na seção anterior.
} 
Quando nos voltamos para análises exploratórias, com o objetivo de verificar se e como as mensagens mais pessimistas e mais otimistas afetam diferentes grupos sociodemográficos, encontramos - na maioria das vezes - resultados consistentes com os resultados gerais não-significantes - ver Tabelas A1, A2, A3 e A4 no apêndice. Nenhum dos dois tratamentos afeta, de forma significante, as percepções dos respondentes de diferentes grupos sociodemográficos com relação ao quão preocupante julgam ser a epidemia nacional e a se enxergam as medidas de isolamento social um exagero. Contudo, efeitos interessantes são encontrados para a probabilidade de se intensificar medidas de prevenção nos próximos dias - ver Figuras 1 e 2, e Tabelas A3 e A4 no apêndice.

Os resultados obtidos com a estimação da equação de regressão (1) para uma amostra restrita aos respondentes que têm até o Ensino Médio completo mostram que uma mensagem mais pessimista causa um aumento de 8,33 pontos percentuais na probabilidade de a pessoa planejar a intensificação de medidas de prevenção nos próximos dias - esse resultado é estatisticamente significante no nível de $5 \%$ (p-valor $=0,0414$ ). Dado que uma pessoa do grupo de controle que possui até o Ensino Médio completo tem uma probabilidade de $91,67 \%$ de planejar a intensificação de medidas de prevenção, esse efeito é suficiente para levar a probabilidade das pessoas designadas a receberem uma mensagem mais pessimista a 100\%. Isso sugere que pessoas com níveis mais baixos de escolaridade são muito sensíveis a mensagens fragmentadas sobre a pandemia. De fato, é necessário somente uma informação mais pessimista - ou mais realista - para que todas as pessoas de baixa escolaridade se engajem no cumprimento de medidas de prevenção intensificadas.

Para pessoas com 60 anos ou mais, uma mensagem mais otimista causa uma redução de 25,66 pontos percentuais na probabilidade de se intensificar medidas de prevenção nos próximos dias e esse resultado é estatisticamente significante no nível de $5 \%$ (p-valor $=0,014$ ). Enquanto o idoso médio do grupo de controle tem uma probabilidade de planejar a intensificação de medidas de prevenção de $91,18 \%$, o idoso médio que foi designado a receber uma mensagem mais otimista tem apenas $65,52 \%$ de probabilidade de fazê-lo. Esse efeito tem uma magnitude muito grande e, porque ele envolve o grupo de alto risco para complicações decorrentes da COVID-19, ele é particularmente importante para informar os formuladores de políticas públicas. Aqui, estamos basicamente dizendo que uma simples mensagem mais otimista pode causar uma não-intensificação de medidas de prevenção - no momento em que o país deve ter suas mais altas taxas de transmissão - por parte das pessoas sensíveis do grupo que carrega o mais alto risco de complicações decorrentes da doença.

Com relação aos resultados obtidos da estimação da equação de regressão (2), encontramos que o efeito de uma mensagem mais pessimista sobre a probabilidade de uma pessoa planejar a intensificação de ações de prevenção é diferente para pessoas que têm níveis mais altos de escolaridade (pelo menos Ensino Superior completo) e pessoas que têm níveis mais baixos de escolaridade (até Ensino Médio completo) - ver Figura 3 e Tabela A5. O efeito de uma mensagem mais pessimista para pessoas com alta escolaridade é 10,55 pontos percentuais menor do que o efeito para pessoas com baixa escolaridade e esse resultado é significante no nível de $5 \%$ (p-valor $=0,0467$ ). Enquanto o efeito marginal da mensagem mais pessimista para pessoas com baixa escolaridade é de 8,33 pontos percentuais, o efeito é de $-2,22$ pontos percentuais para pessoas com alta escolaridade. Esses resultados, combinados com aqueles encontrados com a estimação da equação de regressão (1), nos dizem que, apesar de os dois grupos terem um alto nível de linha de base para a probabilidade de planejar a intensificação de medidas de prevenção nos próximos dias, pessoas com baixa escolaridade são mais sensíveis e apresentam mais espaço para mudanças de comportamento, enquanto pessoas com níveis mais altos de escolaridade são menos sensíveis e tendem a manter o comportamento que planejaram inicialmente. 


\section{FIGURA 1 EFEITO DO TRATAMENTO 1 EM INTENSIFICAÇÃO}

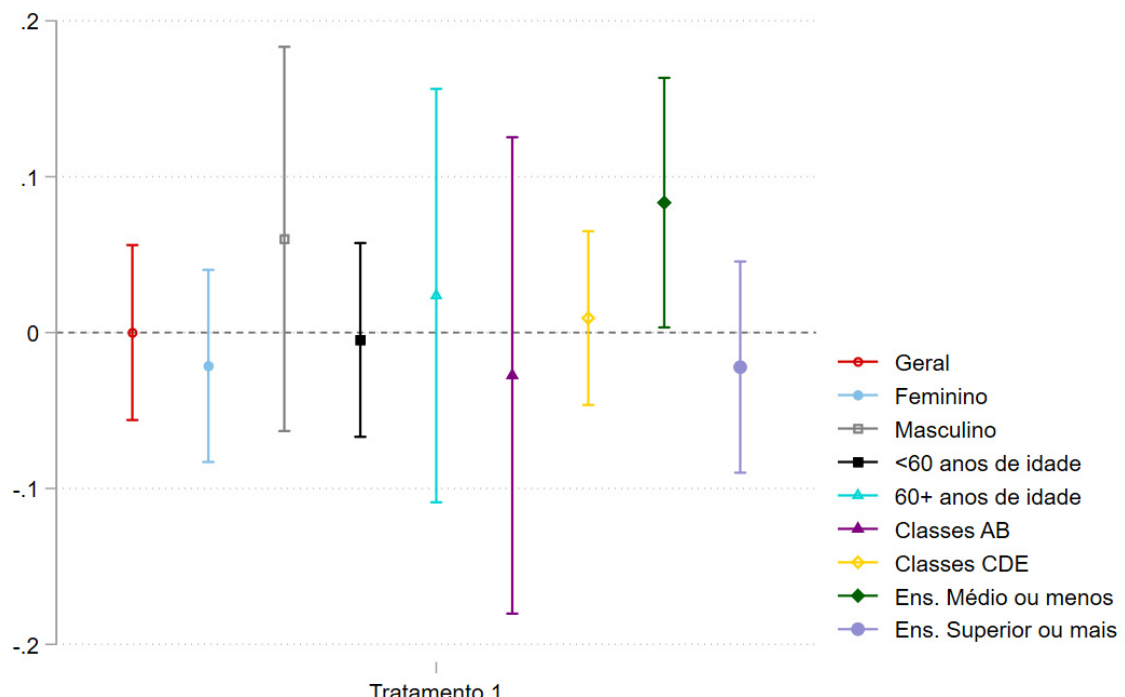

Notas. A figura mostra pontos estimados e intervalos de confiança de $95 \%$. O termo "general" indica o ponto estimado referente à amostra completa.

Fonte: Elaborada pelos autores.

\section{FIGURA 2 EFEITO DO TRATAMENTO 2 EM INTENSIFICAÇÃO}

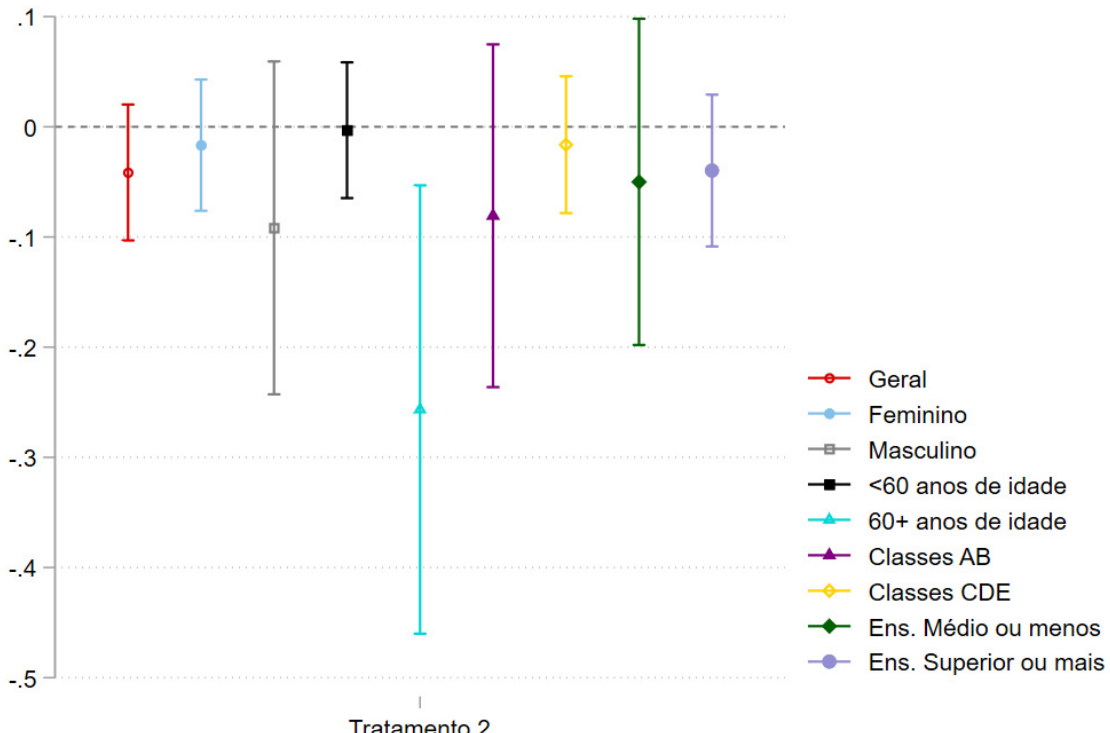

Notas. A figura mostra pontos estimados e intervalos de confiança de $95 \%$. O termo "general" indica o ponto estimado referente à amostra completa.

Fonte: Elaborada pelos autores. 
Finalmente, com a estimação da equação de regressão (2), também encontramos que o efeito da mensagem mais otimista na probabilidade de intensificação de medidas de prevenção é 25,33 pontos percentuais menor para pessoas com idade de 60 anos ou mais ( $\mathrm{p}$-valor $=0,0172$ ) - ver Figura $4 \mathrm{e}$ Tabela A6. De fato, o efeito marginal de tal mensagem mais otimista para pessoas mais jovens é -0,31 ponto percentual, enquanto o efeito marginal para idosos é -25,66 pontos percentuais. A combinação desses resultados com aqueles obtidos com a estimação da equação (1) nos diz que, na média, idosos tendem a desistir da intensificação de medidas de prevenção quando apresentados com uma mensagem mais otimista. Pessoas mais jovens, no entanto, tendem a manter o comportamento já planejado quando são apresentadas com fatos mais otimistas.

\section{FIGURA 3 EFEITOS HETEROGÊNEOS DO TRATAMENTO 1 EM INTENSIFICAÇÃO}

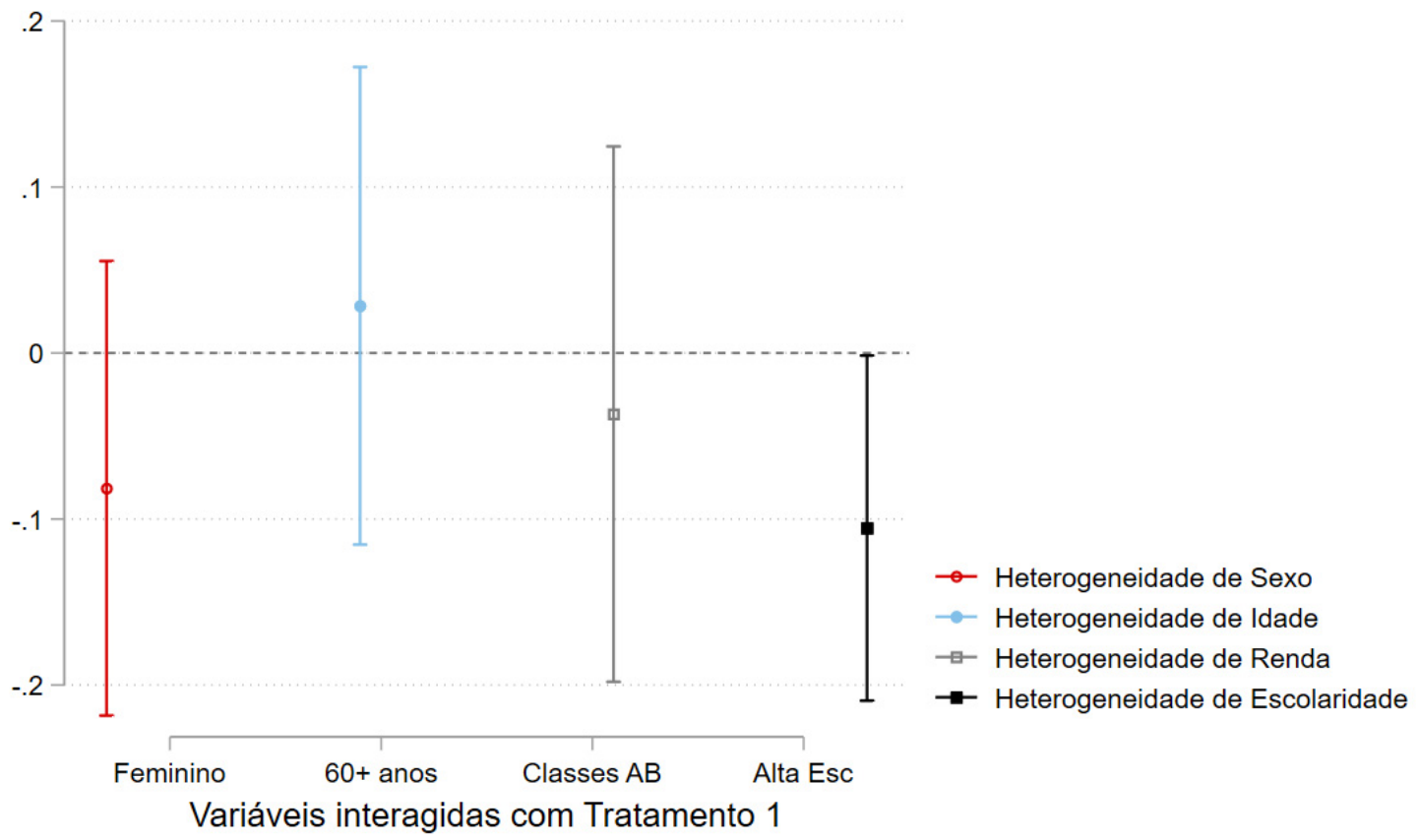

Notas. A figura apresenta pontos estimados e intervalos de confiança de 95\%. Fonte: Elaborada pelos autores. 


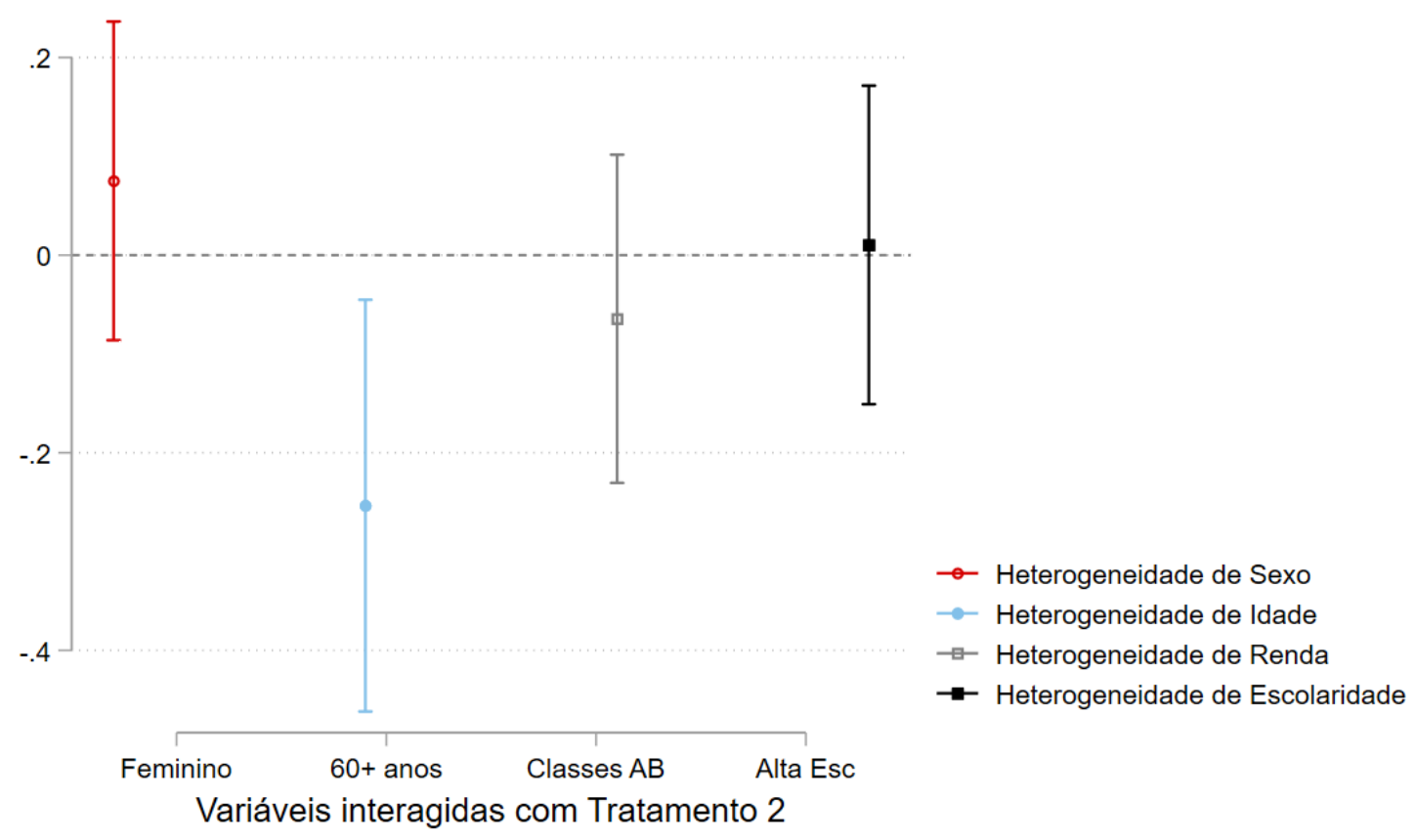

Notas. A figura apresenta pontos estimados e intervalos de confiança de $95 \%$. Fonte: Elaborada pelos autores.

\section{IMPLICAÇÕES}

Neste artigo, utilizamos um experimento aleatorizado em uma plataforma de pesquisa para verificar como as pessoas reagem a informações fragmentadas durante uma crise de pandemia, quando elas estão a enfrentar intensa má comunicação governamental. Nossos resultados principais revelam que apresentar mensagens quebradas sobre a pandemia, mais pessimistas ou mais otimistas, não tem um efeito médio significante em percepções e comportamentos planejados dos participantes. Esses resultados sugerem que, na média, os brasileiros, que têm um perfil parecido com o perfil do respondente médio dessa pesquisa, não são sensíveis a informações fragmentadas quando enfrentam um momento de má comunicação governamental. De fato, esses brasileiros se mantêm fiéis a suas percepções e seus comportamentos planejados.

A insensibilidade desses cidadãos brasileiros a mensagens fragmentadas pode ser favorável se eles estiverem trilhando um caminho na direção desejada para contenção da disseminação do vírus. No entanto, essa insensibilidade pode também ser muito prejudicial quando os cidadãos estão, inflexivelmente, indo na direção contrária; isto porque, nesse caso, tal insensibilidade pode fazer com que as pessoas não reajam a certas informações quando elas, na verdade, deveriam - para o melhor de todos.

Apesar de o efeito médio geral encontrado não ser significante, resultados interessantes são encontrados quando restringimos as análises a grupos sociodemográficos específicos. As pessoas 
de baixa escolaridade e as pessoas com idade de 60 anos ou mais - aquelas que formam o grupo de alto risco para complicações decorrentes da COVID-19 - parecem ser mais sensíveis a informações fragmentadas. Indivíduos de baixa escolaridade reagem a fatos mais pessimistas sobre a pandemia com uma probabilidade mais alta de intensificar medidas de prevenção. E, pessoas com idade de 60 anos ou mais, quando expostas a mensagens mais otimistas, reagem com uma probabilidade mais baixa de intensificar as ações para prevenir a contaminação, potencialmente minando a eficácia de chamadas para estimular o isolamento social.

Mesmo reconhecendo as limitações deste estudo em termos de validade externa e tamanho amostral, vale ressaltar que a abordagem experimental garante a sua validade interna. Ainda que, na média, os respondentes não se mostrem sensíveis a mensagens fragmentadas, os efeitos causais encontrados para grupos sociodemográficos específicos mostram a importância de estratégias de comunicação acuradas e compreensivas, focadas em influenciar tanto as percepções dos cidadãos quanto as medidas por eles tomadas para conter a epidemia nacional. Os resultados sugerem que a provisão de informações contraditórias por oficiais do governo e veículos de mídia pode minar os esforços colaborativos dos cidadãos, necessários para a coprodução de serviços públicos, pelo menos para alguns grupos sociodemográficos. Desta forma, seguir recomendações com base em evidência e apresentar à população informações consistentes e completas, com o objetivo de adequadamente influenciar seu comportamento, pode somente ajudar a amenizar os efeitos colaterais da pandemia sobre a economia; apesar de que essas medidas podem não ser suficientes quando as pessoas já assumiram uma posição inflexível diante da situação.

De um ponto de vista teórico, nosso trabalho contribui para a discussão sobre o desenho de uma comunicação efetiva para promover esforços colaborativos de indivíduos e organizações para alcançarem um objetivo comum (Ansell \& Gash, 2018), mesmo em contextos onde a rivalidade política está presente (Cabral \& Krane, 2018). Adicionalmente, nós contribuímos com a literatura emergente de gestão de desastres na Administração Pública (Kapucu \& Garayev, 2011; Boin \& Lodge, 2016), ao trazer consciência para novas perspectivas sobre comunicação em tempos de pandemia. Dependendo do nível de sensibilidade das pessoas a mensagens fragmentadas, elas podem ou não reagir a novos estímulos de informação, demandando então uma estratégia de comunicação mais sofisticada da parte dos oficiais do governo, para que possam influenciar as pessoas a agirem. 


\section{REFERÊNCIAS}

Anderson, R., Heesterbeek, H., Klinkenberg, D., \& Hollingsworth, T. (2020, março 21). How will country-based mitigation measures influence the course of the COVID-19 epidemic? The Lancet, 395(10228), 931-934. Recuperado de https://doi. org/10.1016/S0140-6736(20)30567-5

Ansell, C., \& Gash, A. (2018). Collaborative platforms as a governance strategy. Journal of Public Administration Research and Theory, 28(1), 16-32.

Boin, A., \& Lodge, M. (2016). Designing resilient institutions for transboundary crisis management: A time for public administration. Public Administration, 94(2), 289-298.

Bovaid, T. (2007). Beyond engagement and participation: User and community coproduction of public services. Public Administration Review, 67(5), 846-860.

Bursztyn, L., Egorov, G., \& Fiorin, S. (2020, março). From extreme to mainstream: The erosion of social norms. Recuperado de https://home.uchicago. edu/bursztyn/Bursztyn_Egorov_Fiorin_Extreme_ Mainstream_2020_03_26.pdf

Cabral, S., \& Krane, D. (2018). Civic festivals and collaborative governance. International Review of Administrative Sciences, 84(1), 185-205.

Chaomin Wu, M., Xiaoyan Chen, M., Yanping Cai, M., Jia’an Xia, M., Xing Zhou, M., \& Sha Xu, M. (2020, março 13). Risk Factors Associated With Acute Respiratory Distress Syndrome and Death in Patients With Coronavirus Disease 2019 Pneumonia in Wuhan, China. Jama Internal Medicine. Recuperado de https://doi.org/10.1001/ jamainternmed.2020.0994

Chong, D., \& Druckman, J. (2010, novembro). Dynamic Public Opinion: Communication Effects over Time. American Political Science Review, 104(4). Recuperado de https://doi.org/10.1017/ S0003055410000493

Clark, B., Brudney, J., \& Jang, S. (2013). Coproduction of government services and the new information technology: Investigating the distributional biases. Public Administration Review, 73(5), 687-701.
Coletta, R. (2020, março 24). Em pronunciamento, Bolsonaro critica fechamento de escolas, ataca governadores e culpa mídia. Folha de S. Paulo. Recuperado de https://www1.folha.uol.com.br/ poder/2020/03/em-pronunciamento-bolsonarocritica-fechamento-de-escolas-ataca-governadorese-culpa-midia.shtml

Comfort, L., Waugh, W., \& Cigler, B. (2012). Emergency management research and practice in public administration: Emergence, evolution, expansion, and future directions. Public Administration Review, 72(4), 539-547.

Correia, S., Luck, S., \& Verner, E. (2020, março 26). Pandemics Depress the Economy, Public Health Interventions Do Not: Evidence from the 1918 Flu. Recuperado de https://dx.doi.org/10.2139/ ssrn. 3561560

Greenstone, M., \& Nigam, V. (2020, March). Does Social Distancing Matter? Recuperado de https://papers.ssrn.com/sol3/papers.cfm?abstract_ $\mathrm{id}=3561244$

Gross, K. (2008, fevereiro 29). Framing Persuasive Appeals: Episodic and Thematic Framing, Emotional Response, and Policy Opinion. Political Psychology, 9(2), 169-192. Recuperado de https://doi. org/10.1111/j.1467-9221.2008.00622.x

Kapucu, N., \& Garayev, V. (2011). Collaborative decision-making in emergency and disaster management. International Journal of Public Administration, 34(6), 366-375.

McLennan, B. (2018). Conditions for effective coproduction in community-led disaster risk management. VOLUNTAS: International Journal of Voluntary and Nonprofit Organizations, 1-17.

Onder, G., Rezza, G., \& Brusaferro, S. (2020, março 23). Case-Fatality Rate and Characteristics of Patients Dying in Relation to COVID-19 in Italy. Jama Internal Medicine. Recuperado de https://doi. org/10.1001/jama.2020.4683

Shareef, M., Dwivedi, Y., Mahmud, R., Wright, A., Rahman, M., Kizgin, H., \& Rana, N. (2019). Disaster management in Bangladesh: developing an effective emergency supply chain network. Annals of Operations Research, 283(1), 1463-1487.

Walker, P., Whittaker, C., Watson, O., Baguelin, M., Ainslie, K., Bhatia, S., ... Boonyasiri, A. (2020, março 
RAP | Pandemias e comunicação: uma avaliação experimental

26). The Global Impact of COVID-19 and Strategies for Mitigation and Suppression. London, UK: WHO Collaborating Centre for Infectious Disease Modelling, MRC Centre for Global, Infectious Disease Analysis, Abdul Latif Jameel Institute for Disease and Emergency Analytics, Imperial College London.
World Health Organization. (2020, março 19). Risk communication and community engagement readiness and response to coronavirus disease (COVID-19). Interim guidance. Recuperado de https://apps.who.int/iris/bitstream/ handle/10665/331513/WHO-2019-nCoV-RCCE2020.2-eng.pdf? sequence $=1$ \&isAllowed $=y$

\section{Carolina Melo}

https://orcid.org/0000-0003-0580-2531

Mestre em Administração Pública e Doutoranda em Economia dos Negócios pelo Insper Instituto de Ensino e Pesquisa. E-mail: carolinapgm1@insper.edu.br

\section{Sandro Cabral}

https://orcid.org/0000-0002-8663-2441

Doutor em Administração de Empresas e Professor Associado do Insper Instituto de Ensino e Pesquisa.

E-mail: sandroc2@insper.edu.br 


\section{APÊNDICE}

\section{FIGURA A1 EFEITO D0 TRATAMENTO 1 EM PREOCUPANTE}

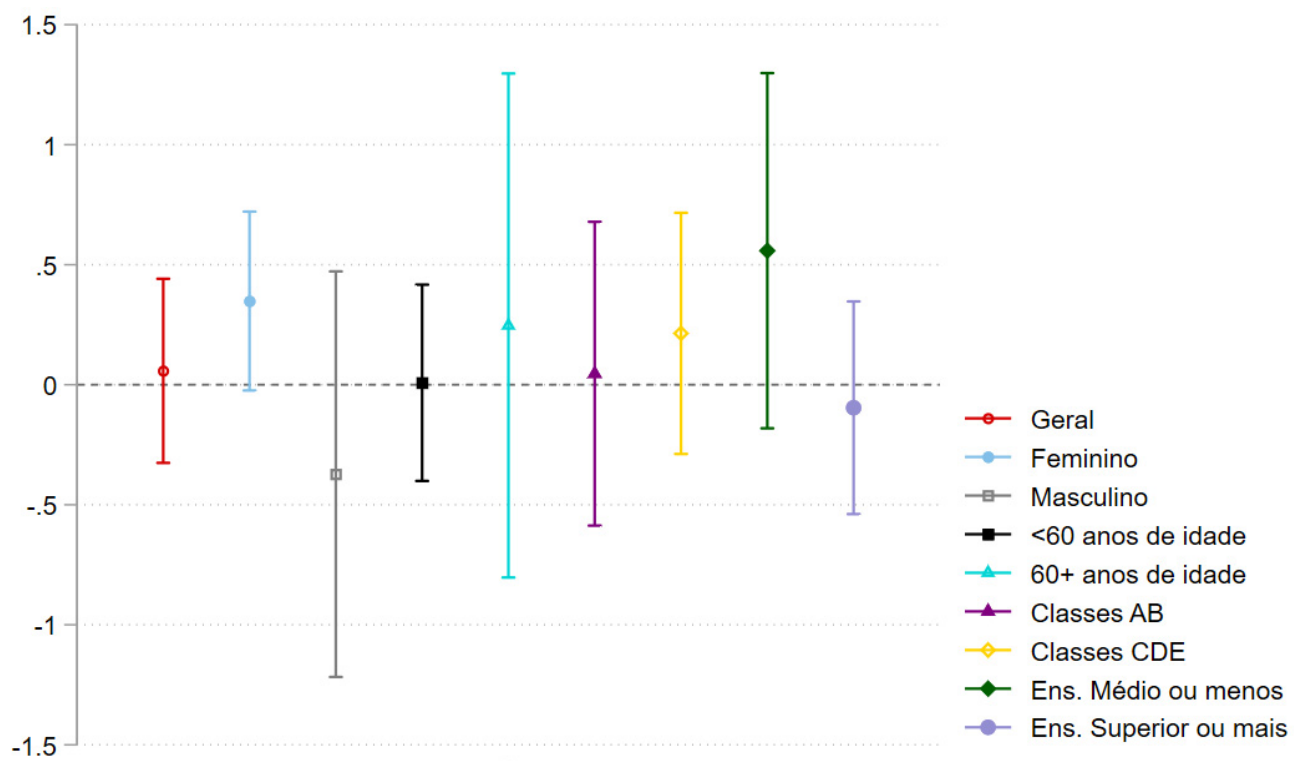

Notas. A figura mostra pontos estimados e intervalos de confiança de 95\%. O termo "general" indica o ponto estimado referente à amostra completa.

Fonte: Elaborada pelos autores.

\section{FIGURA A2 EFEITO DO TRATAMENTO 2 EM PREOCUPANTE}

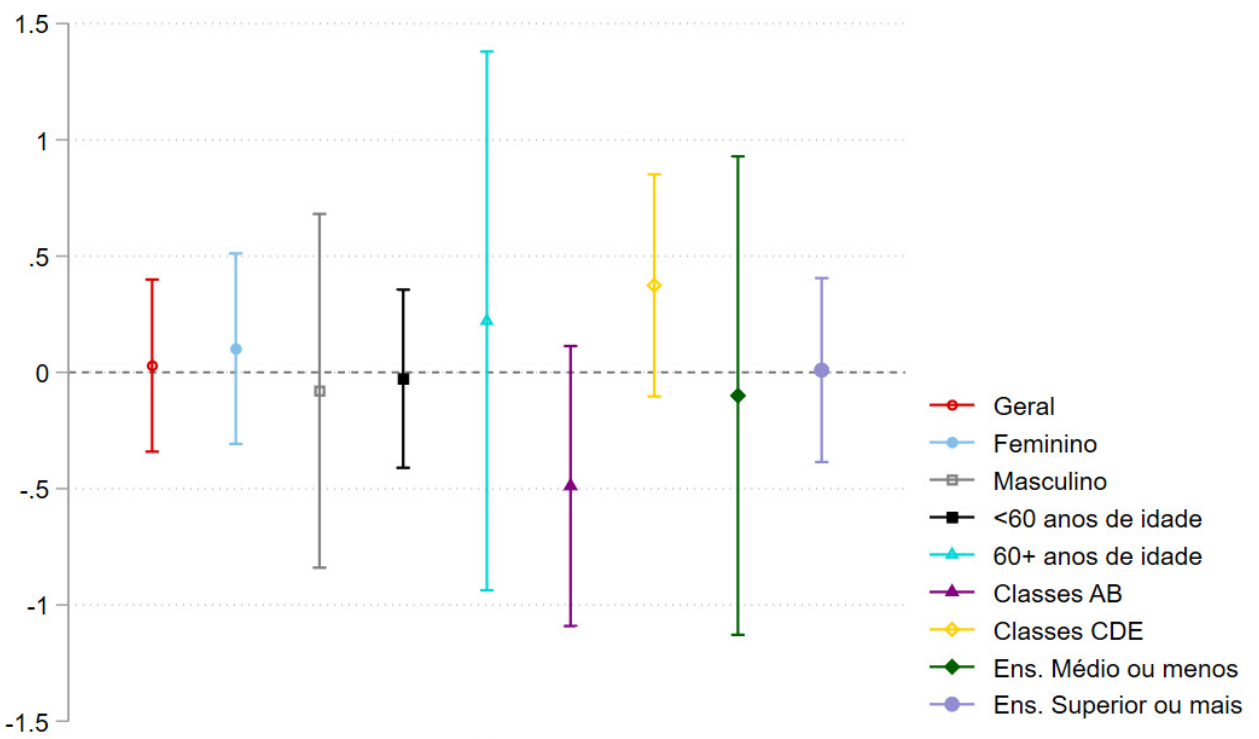

Tratamento 2

Notas. A figura mostra pontos estimados e intervalos de confiança de 95\%. O termo "general" indica o ponto estimado referente à amostra completa.

Fonte: Elaborada pelos autores. 


\section{FIGURA A3 EFEITO DO TRATAMENTO 1 EM EXAGERO}

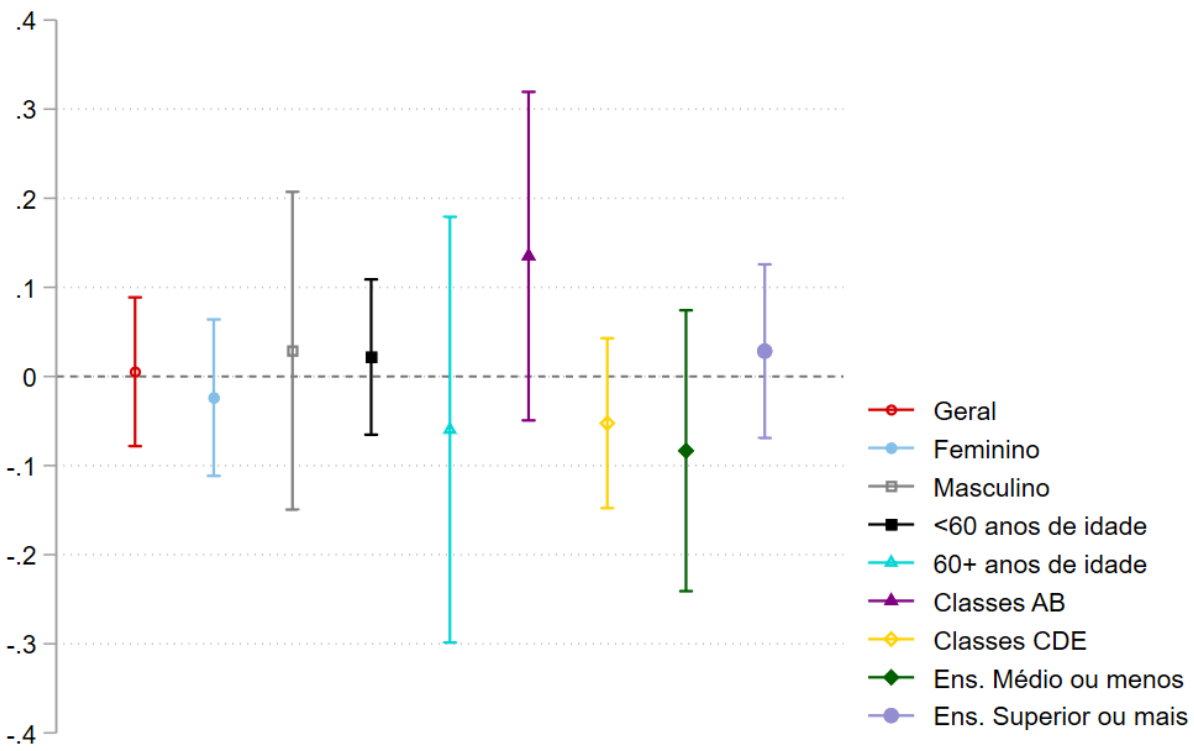

Tratamento 1

Notas. A figura mostra pontos estimados e intervalos de confiança de $95 \%$. O termo "general" indica o ponto estimado referente à amostra completa.

Fonte: Elaborada pelos autores.

\section{FIGURA A4 EFEITO DO TRATAMENTO 2 EM EXAGERO}

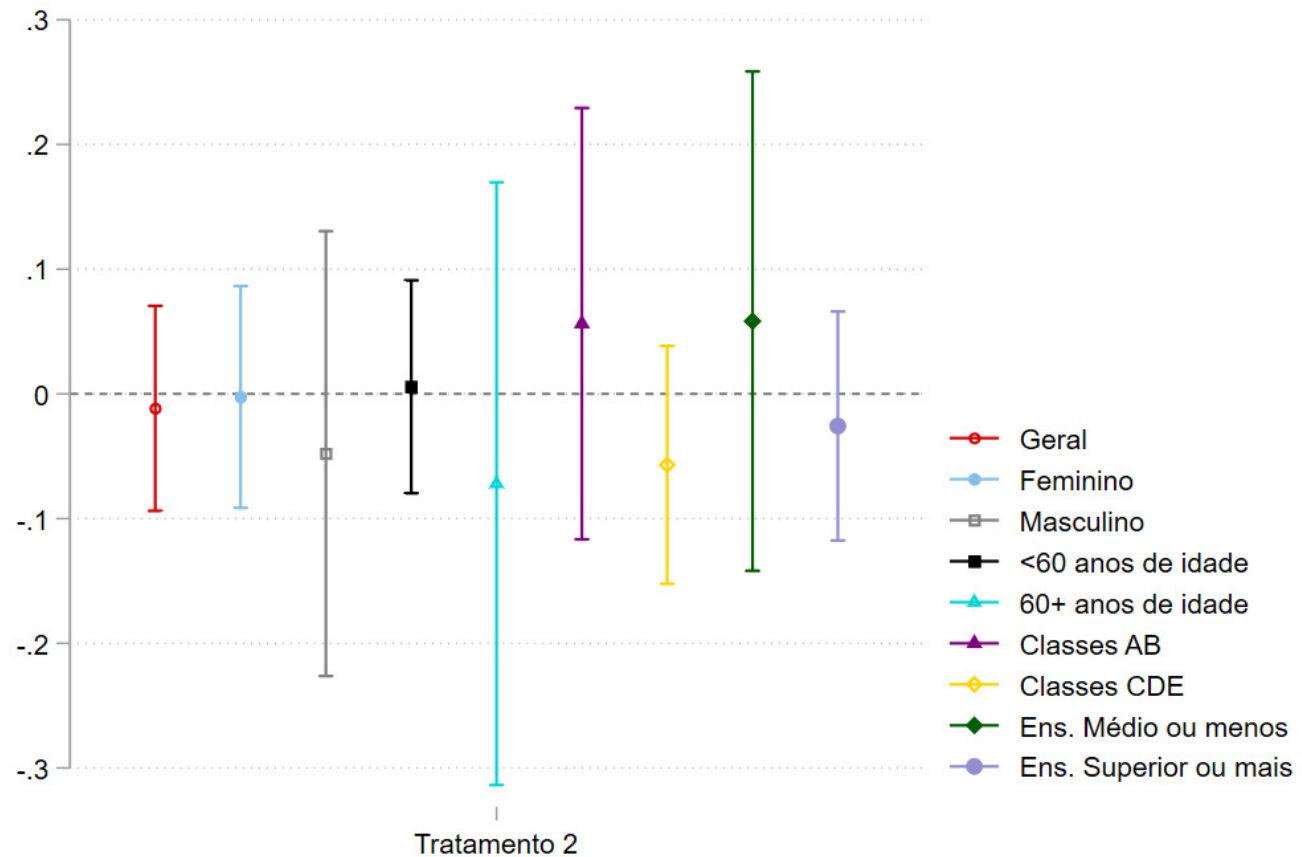

Notas. A figura mostra pontos estimados e intervalos de confiança de $95 \%$. O termo "general" indica o ponto estimado referente à amostra completa.

Fonte: Elaborada pelos autores. 
RAP | Pandemias e comunicação: uma avaliação experimental

\section{TABELA A1 ESTATÍSTICAS DESCRITIVAS POR GRUPO}

\begin{tabular}{|c|c|c|c|c|c|c|c|c|c|}
\hline \multirow{2}{*}{ Variável } & \multicolumn{3}{|c|}{ Grupo de Tratamento 1} & \multicolumn{3}{|c|}{ Grupo de Tratamento 2} & \multicolumn{3}{|c|}{ Grupo de Controle } \\
\hline & Média & $\mathrm{DP}$ & Obs & Média & DP & Obs & Média & DP & Obs \\
\hline Preocupante & 8.5105 & 1.8961 & 190 & 8.482 & 1.765 & 191 & 8.4526 & 1.9094 & 190 \\
\hline Exagero & 0.2211 & 0.4161 & 190 & 0.204 & 0.404 & 191 & 0.2158 & 0.4125 & 190 \\
\hline Intensificação & 0.9158 & 0.2784 & 190 & 0.874 & 0.332 & 191 & 0.9158 & 0.2784 & 190 \\
\hline Idade & 41.4526 & 15.4617 & 190 & 41.241 & 14.974 & 191 & 41.5105 & 15.4956 & 190 \\
\hline $60+$ anos & 0.1632 & 0.3705 & 190 & 0.152 & 0.360 & 191 & 0.1789 & 0.3843 & 190 \\
\hline Feminino & 0.6632 & 0.4739 & 190 & 0.702 & 0.459 & 191 & 0.7263 & 0.4470 & 190 \\
\hline Branca & 0.7000 & 0.4595 & 190 & 0.696 & 0.461 & 191 & 0.6842 & 0.4661 & 190 \\
\hline Preta & 0.0316 & 0.1753 & 190 & 0.063 & 0.243 & 191 & 0.0474 & 0.2130 & 190 \\
\hline Amarela & 0.0263 & 0.1605 & 190 & 0.026 & 0.160 & 191 & 0.0263 & 0.1605 & 190 \\
\hline Parda & 0.2211 & 0.4161 & 190 & 0.209 & 0.408 & 191 & 0.2316 & 0.4230 & 190 \\
\hline Indígena & 0.0000 & 0.0000 & 190 & 0.000 & 0.000 & 191 & 0.0053 & 0.0725 & 190 \\
\hline Ensino Fund. & 0.0053 & 0.0725 & 190 & 0.005 & 0.072 & 191 & 0.0105 & 0.1023 & 190 \\
\hline Ensino Médio & 0.2053 & 0.4050 & 190 & 0.152 & 0.360 & 191 & 0.2421 & 0.4295 & 190 \\
\hline Ensino Superior & 0.3789 & 0.4864 & 190 & 0.335 & 0.473 & 191 & 0.3684 & 0.4837 & 190 \\
\hline Pós-graduação & 0.4105 & 0.4932 & 190 & 0.508 & 0.501 & 191 & 0.3789 & 0.4864 & 190 \\
\hline Classes AB & 0.2759 & 0.4482 & 174 & 0.305 & 0.462 & 177 & 0.2890 & 0.4546 & 173 \\
\hline
\end{tabular}

Fonte: Elaborada pelos autores.

\section{TABELA A2 TESTES DE BALANCEAMENTO}

\begin{tabular}{l|ccc|c|c|c|c}
\hline Variável & Trat 1 & Erro Padrão & p-valor & Trat 2 & Erro Padrão & p-valor & N \\
\hline Idade & -0.0579 & 1.5881 & 0.9709 & -0.2697 & 1.5613 & 0.8629 & 571 \\
\hline $60+$ anos & -0.0158 & 0.0387 & 0.6836 & -0.0271 & 0.0381 & 0.4775 & 571 \\
Feminino & -0.0632 & 0.0473 & 0.1820 & -0.0247 & 0.0464 & 0.5941 & 571 \\
Branca & 0.0158 & 0.0475 & 0.7396 & 0.0121 & 0.0475 & 0.7986 & 571 \\
Preta & -0.0158 & 0.0200 & 0.4305 & 0.0155 & 0.0234 & 0.5095 & 571 \\
\hline
\end{tabular}


RAP | Pandemias e comunicação: uma avaliação experimental

\begin{tabular}{|c|c|c|c|c|c|c|c|}
\hline Variável & Trat 1 & Erro Padrão & $\mathrm{p}$-valor & Trat 2 & Erro Padrão & p-valor & $\mathrm{N}$ \\
\hline Amarela & 0.0000 & 0.0165 & 1.0000 & -0.0001 & 0.0164 & 0.9933 & 571 \\
\hline Parda & -0.0105 & 0.0430 & 0.8069 & -0.0222 & 0.0426 & 0.6030 & 571 \\
\hline Indígena & -0.0053 & 0.0053 & 0.3177 & -0.0053 & 0.0053 & 0.3177 & 571 \\
\hline Ensino Fund. & -0.0053 & 0.0091 & 0.5632 & -0.0053 & 0.0091 & 0.5605 & 571 \\
\hline Ensino Médio & -0.0368 & 0.0428 & 0.3900 & -0.0903 & 0.0406 & 0.0266 & 571 \\
\hline Ensino Superior & 0.0105 & 0.0498 & 0.8325 & -0.0333 & 0.0490 & 0.4967 & 571 \\
\hline Pós-graduação & 0.0316 & 0.0503 & 0.5300 & 0.1289 & 0.0506 & 0.0111 & 571 \\
\hline Classes AB & -0.0132 & 0.0485 & 0.7862 & 0.0161 & 0.0490 & 0.7430 & 524 \\
\hline
\end{tabular}

Notas. Testes de balanceamento foram realizados com a equação de regressão (1), usando variáveis sociodemográficas como variáveis de resultado. Erros-padrão são robustos.

Fonte: Elaborada pelos autores.

\section{TABELA A3 EFEITOS DOS TRATAMENTOS PARA PESSOAS QUE POSSUEM ATÉ 0 ENSINO MÉDIO COMPLETO}

\begin{tabular}{|c|c|c|c|c|c|c|}
\hline & (1) & (2) & (3) & (4) & (5) & (6) \\
\hline & Preocupante & Preocupante & Exagero & Exagero & Intensificação & Intensificação \\
\hline Trat 1 & 0.5583 & 0.4865 & -0.0833 & -0.0556 & 0.0833 & 0.0840 \\
\hline Erro Padrão & 0.3735 & 0.4016 & 0.0796 & 0.0889 & 0.0404 & 0.0564 \\
\hline p-valor & 0.1377 & 0.2290 & 0.2972 & 0.5330 & 0.0414 & 0.1398 \\
\hline Trat 2 & -0.1000 & -0.2889 & 0.0583 & 0.0250 & -0.0500 & -0.0581 \\
\hline Erro Padrão & 0.5194 & 0.6195 & 0.1011 & 0.1107 & 0.0747 & 0.0811 \\
\hline p-valor & 0.8477 & 0.6422 & 0.5649 & 0.8219 & 0.5048 & 0.4758 \\
\hline Constante & 8.1667 & 13.3564 & 0.2083 & 0.3736 & 0.9167 & 1.2663 \\
\hline Erro Padrão & 0.3034 & 1.6430 & 0.0594 & 0.3062 & 0.0404 & 0.1769 \\
\hline p-valor & 0.0000 & 0.0000 & 0.0006 & 0.2257 & 0.0000 & 0.0000 \\
\hline N & 118 & 106 & 118 & 106 & 118 & 106 \\
\hline Controles & NO & YES & NO & YES & NO & YES \\
\hline
\end{tabular}

Notas. Estimações referentes à equação de regressão (1). O conjunto de controles inclui todas as variáveis sociodemográficas coletadas na pesquisa, com exceção do nível de escolaridade. Erros-padrão são robustos.

Fonte: Elaborada pelos autores. 
RAP | Pandemias e comunicação: uma avaliação experimental

\section{TABELA A4 EFEITOS DOS TRATAMENTOS PARA PESSOAS QUE POSSUEM 60 ANOS OU MAIS DE IDADE}

\begin{tabular}{lcccccc} 
& $(\mathbf{1})$ & $(\mathbf{2})$ & $(\mathbf{3})$ & $(\mathbf{4})$ & $\mathbf{( 5 )}$ & $\mathbf{( 6 )}$ \\
Variável & Preocupante & Preocupante & Exagero & Exagero & Intensificação & Intensificação \\
\hline Trat 1 & 0.2467 & 0.2725 & -0.0598 & -0.0650 & 0.0237 & 0.0931 \\
Erro Padrão & 0.5285 & 0.5730 & 0.1202 & 0.1346 & 0.0667 & 0.0848 \\
p-valor & 0.6418 & 0.6360 & 0.6203 & 0.6306 & 0.7231 & 0.2766 \\
Trat 2 & 0.2211 & 0.1116 & -0.0720 & -0.1161 & -0.2566 & -0.2264 \\
Erro Padrão & 0.5830 & 0.6893 & 0.1216 & 0.1260 & 0.1024 & 0.1203 \\
p-valor & 0.7054 & 0.8719 & 0.5554 & 0.3604 & 0.0140 & 0.0644 \\
Constante & 7.8824 & 9.1066 & 0.3824 & -0.4597 & 0.9118 & -0.0481 \\
Erro Padrão & 0.3506 & 4.8030 & 0.0847 & 0.9388 & 0.0494 & 0.6013 \\
p-valor & 0.0000 & 0.0625 & 0.0000 & 0.6260 & 0.0000 & 0.9365 \\
N & 94 & 85 & 94 & 85 & 94 & 85
\end{tabular}

Notas. Estimações referentes à equação de regressão (1). O conjunto de controles inclui todas as variáveis sociodemográficas coletadas na pesquisa, com exceção da idade. Erros-padrão são robustos.

Fonte: Elaborada pelos autores.

\section{TABELA A5 EFEITOS HETEROGÊNEOS DE TRATAMENTO - BAIXA ESCOLARIDADE VS. ALTA ESCOLARIDADE}

\begin{tabular}{|c|c|c|c|}
\hline Variável & $\begin{array}{c}\text { (1) } \\
\text { Preocupante }\end{array}$ & $\begin{array}{c}(2) \\
\text { Exagero }\end{array}$ & $\begin{array}{c}\text { (3) } \\
\text { Intensificação }\end{array}$ \\
\hline Trat 1 & 0.5583 & -0.0833 & 0.0833 \\
\hline Erro Padrão & 0.3706 & 0.0790 & 0.0401 \\
\hline p-valor & 0.1325 & 0.2917 & 0.0382 \\
\hline Trat 2 & -0.1000 & 0.0583 & -0.0500 \\
\hline Erro Padrão & 0.5154 & 0.1003 & 0.0742 \\
\hline$p$-valor & 0.8462 & 0.5611 & 0.5005 \\
\hline Alta Esc & 0.3826 & 0.0100 & -0.0012 \\
\hline Erro Padrão & 0.3385 & 0.0685 & 0.0465 \\
\hline$p$-valor & 0.2588 & 0.8842 & 0.9799 \\
\hline Trat $1{ }^{\star}$ Alta Esc & -0.6543 & 0.1117 & -0.1055 \\
\hline Erro Padrão & 0.4340 & 0.0933 & 0.0529 \\
\hline
\end{tabular}


RAP | Pandemias e comunicação: uma avaliação experimental

\begin{tabular}{lccc} 
Variável & $\begin{array}{c}(\mathbf{1}) \\
\text { Preocupante }\end{array}$ & $\begin{array}{c}(\mathbf{2}) \\
\text { Exagero }\end{array}$ & $\begin{array}{c}(\mathbf{3}) \\
\text { Intensificação }\end{array}$ \\
\hline p-valor & 0.1322 & 0.2317 & 0.0467 \\
\hline Trat 2*Alta Esc & 0.1097 & -0.0841 & 0.0103 \\
Erro Padrão & 0.5535 & 0.1107 & 0.0821 \\
\hline p-valor & 0.8429 & 0.4477 & 0.9003 \\
Constante & 8.1667 & 0.2083 & 0.9167 \\
\hline Erro Padrão & 0.3011 & 0.0589 & 0.0401 \\
\hline p-valor & 0.0000 & 0.0004 & 0.0000 \\
\hline N & 571 & 571 & 571
\end{tabular}

Notas. Estimações referentes à equação de regressão (2). Alta Esc é uma variável binária que toma o valor de 1 se o nível mais alto de escolaridade que a pessoa completou é o Ensino Superior ou a Pós-graduação, e toma o valor de 0 caso contrário. Erros-padrão são robustos.

Fonte: Elaborada pelos autores.

\section{TABELA A6 EFEITOS HETEROGÊNEOS DE TRATAMENTO - JOVEM VS. IDOSO}

\begin{tabular}{llll}
\hline Variável & $(1)$ & $(2)$ & \multicolumn{1}{c}{$(3)$} \\
\hline Trat 1 & Preocupante & Exagero & Intensificação \\
\hline Erro Padrão & 0.0080 & 0.0218 & -0.0047 \\
p-valor & 0.2085 & 0.0445 & 0.0317 \\
\hline Treat 2 & 0.9695 & 0.6245 & 0.8818 \\
\hline Erro Padrão & -0.0275 & 0.0057 & -0.0031 \\
\hline p-valor & 0.1953 & 0.0435 & 0.0314 \\
\hline Idoso & 0.8879 & 0.8959 & 0.9218 \\
\hline Erro Padrão & -0.6946 & 0.2029 & -0.0049 \\
\hline -valor & 0.3776 & 0.0893 & 0.0537 \\
\hline Trat 1*Idoso & 0.0664 & 0.0235 & 0.9273 \\
\hline Erro Padrão & 0.2387 & -0.0815 & 0.0284 \\
\hline p-valor & 0.5628 & 0.1270 & 0.0732 \\
\hline Trat 2*Idoso & 0.6716 & 0.5210 & 0.6980 \\
\hline & 0.2486 & -0.0777 & -0.2535 \\
\hline
\end{tabular}


RAP | Pandemias e comunicação: uma avaliação experimental

\begin{tabular}{lccc} 
& $(1)$ & $(2)$ & $(3)$ \\
Variável & Preocupante & Exagero & Intensificação \\
\hline Erro Padrão & 0.6088 & 0.1280 & 0.1061 \\
\hline -valor & 0.6832 & 0.5439 & 0.0172 \\
Constante & 8.5769 & 0.1795 & 0.9167 \\
Erro Padrão & 0.1495 & 0.0309 & 0.0222 \\
p-valor & 0.0000 & 0.0000 & 0.0000 \\
N & 571 & 571 & 571
\end{tabular}

Notas. Estimações referentes à equação de regressão (2). Idoso é uma variável binária que toma o valor de 1 se a pessoa possui 60 anos de idade ou mais, e toma o valor de 0 caso contrário. Erros-padrão são robustos. Fonte: Elaborada pelos autores. 